\section{References}

Azokpota, C., Calvarin, G. \& Pommier, G. (1976). $J$. Chem. Thermodyn. 8, 283-287.

Bohn, R. K. \& HaAland, A. (1966). J. Organomet. Chem. 5, 470-476.

BÜNDER, W. \& WeIss, E. (1975a). J. Organomet. Chem. 92 , 65-68.

BÜNDER, W. \& Weiss, E. (1975b). J. Organomet. Chem. 92 , $1-6$.

Calvarin, G. \& Bérar, J. F. (1975). J. Appl. Cryst. 8, 380385.

Calvarin, G. \& Weigel, D. (1976). J. Appl. Cryst. 9, 212215.

Campbell, A. J., Fyfe, C. A., Harold-Smith, D. \& JeFFREY, K. R. (1976). Mol. Cryst. Liq. Cryst. 36, 1-23.

Clec'H, G., Calvarin, G., Bérar, J. F. \& KahN, R. (1978). C. R. Acad. Sci. Sér. C, 286, 315-317.

Dunitz, J. D. \& ORGEL, L. E. (1953). Nature (London), 171, 121-122.

Dunitz, J. D., Orgel, L. E. \& Rich, A. (1956). Acta Cryst. 9, 373-375.

Dunitz, J. D. \& Seiler, P. (1973). Acta Cryst. B29, 589595.

Edwards, J. W., Kington, G. L. \& Mason, R. (1960). Trans. Faraday Soc. 56, 660-667.
Eiland, P. F. \& Pepinsky, R. (1952). J. Am. Chem. Soc. 74, 4971 .

Fischer, E. O. \& Pfab, W. (1952). Z. Naturforsch. Teil B, 7, 377-379.

HaAland, A. (1968). Acta Chem. Scand. 22, 3030-3032.

HaAland, A. \& Nilsson, J. E. (1968). Acta Chem. Scand. $22,2653-2670$.

Holm, C. H. \& Ibers, J. A. (1959). J. Chem. Phys. 30, 885888.

Hyams, I. J. \& Ron, A. (1973). J. Chem. Phys. 59, 30273030.

JoHnson, C. K. (1965). ORTEP. Report ORNL-3794. Oak Ridge National Laboratory, Tennessee.

Mulay, L. N. \& Attalla, A. (1963). J.Am. Chem. Soc. 85, 702-706.

Takusagawa, F. \& Koetzle, T. F. (1979). Acta Cryst. B35, 1074-1081.

Willis, B. T. M. (1960). Acta Cryst. 13, 1088.

WILLIS, B. T. M. (1961). AERE Report R3708, Harwell, Oxfordshire, England.

Winter, W. K., Curnette, B. \& Whitcomb, G. E. (1959). Spectrochim. Acta, 12, 1085-1102.

Wong, C., Lee, T. Y., ChaO, K. J. \& LeE, S. (1972). Acta Cryst. B28, 1662-1665.

Wong, C., Lee, T. Y., Lee, T. J., Chang, T. W. \& Liv, C. S. (1973). Inorg. Nucl. Chem. Lett. 9, 667-673.

Acta Cryst. (1979). B35, 1074-1081

\title{
A Neutron Diffraction Study of the Crystal Structure of Ferrocene*
}

\author{
By Fusao Takusagawa and Thomas F. Koetzle $\dagger$ \\ Chemistry Department, Brookhaven National Laboratory, Upton, New York 11973, USA
}

(Received 14 October 1978; accepted 21 November 1978)

\begin{abstract}
The structure of ferrocene has been refined with singlecrystal neutron diffraction data measured at temperatures of 173 and $298 \mathrm{~K}\left[\mathrm{Fe}\left(\eta^{5}-\mathrm{C}_{5} \mathrm{H}_{5}\right)_{2}, \mathrm{C}_{10} \mathrm{H}_{10} \mathrm{Fe}\right.$, space group $P 2_{1} / a, Z=2$ ]. The positions of all $\mathrm{H}$ atoms have been varied in the refinements. The cyclopentadienyl ligands are found to be significantly non-planar, with the $\mathrm{H}$ atoms displaced toward the $\mathrm{Fe}$ atom, in agreement with the results of earlier electron diffraction studies [Bohn \& Haaland (1966). J. Organomet. Chem. 5, 470-476; Haaland \& Nilsson (1968). Acta Chem. Scand. 22, 2653-2670]. The crystal structure is dis-

\footnotetext{
* Research carried out at Brookhaven National Laboratory under contract with the US Department of Energy and supported by its Office of Basic Energy Sciences.

† To whom correspondence should be addressed.
}

ordered, as indicated by Willis's original neutron diffraction measurements [Willis (1960). Acta Cryst. 13, 1088; (1961). AERE Report R3708, Harwell, Oxfordshire, England]. In the present work, refinements were carried out by three procedures: $(A)$ conventional refinement with anisotropic thermal parameters introduced for all atoms, $(B)$ extension of $(A)$ to include third- and fourthorder thermal tensors for $\mathbf{C}$ and $\mathbf{H}$ atoms, and $(C)$ refinement with the cyclopentadienyl ligands assumed to occupy two disordered positions. Based upon the results of these refinements and rigid-body-motion analyses of the thermal parameters, it appears that the disorder of the cyclopentadienyl rings results from the presence of molecules in different orientations randomly distributed throughout the crystal. A similar conclusion has been reached from X-ray diffraction data [Seiler \& Dunitz (1979). Acta Cryst. B35, 10681074]. 


\section{Introduction}

The early X-ray diffraction studies of ferrocene (Fischer \& Pfab, 1952; Eiland \& Pepinsky, 1952; Dunitz \& Orgel, 1953) established the sandwich structure, and indicated that the cyclopentadienyl ligands should be staggered, since the $\mathrm{Fe}$ atom lies at a center of inversion in space group $P 2_{1} / a$. The structure was subsequently refined with three-dimensional X-ray data (Dunitz, Orgel \& Rich, 1956; hereinafter DOR). However, a variety of evidence has been presented to indicate that the crystal structure is disordered at room temperature. In particular, the heat-capacity data of Edwards, Kington \& Mason (1960) showed that a $\lambda$ point transition occurs at $164 \mathrm{~K}$; this transition has been associated with an onset of rotational disorder of the cyclopentadienyl rings. The original neutron diffraction measurements (Willis, 1960, 1961) were interpreted in terms of a disordered model, with one-third of the rings occupying positions rotated $36^{\circ}$ with respect to the DOR structure. Also, an electron diffraction study (Bohn \& Haaland, 1966) indicated that ferrocene in the gas phase has an eclipsed equilibrium configuration. The barrier to internal rotation was estimated to be 3.8 (13) $\mathrm{kJ} \mathrm{mol}^{-1}$ (Haaland \& Nilsson, 1968). In the crystal, the tendency of individual molecules to prefer the eclipsed configuration must be modified by intermolecular forces. Campbell, Fyfe, Harold-Smith \& Jeffrey (1976) have calculated the contribution from non-bonded interactions to the potential energy of ferrocene in the solid state, and have concluded that at low temperatures the non-bonded interactions cause the staggered (DOR) configuration to be favored, while at higher temperatures the strength of these interactions is diminished due to lattice expansion, and a disordered structure results.

We felt that a new neutron diffraction study of ferrocene was warranted. Firstly, we wished to determine whether the protons were bent out of the planes of the cyclopentadienyl rings, as indicated by the electron diffraction results. This question was not directly addressed by Willis $(1960,1961)$, whose neutron data were somewhat limited in resolution. Secondly, we wished to make detailed examination of the disorder in the structure. Therefore, we have carried out neutron diffraction measurements at 173 and $298 \mathrm{~K}$, and results of these investigations are reported here. We have also performed an X-ray study at $298 \mathrm{~K}$; our data lead to structural models in essential agreement with the results of the X-ray investigation in the preceding paper (Seiler \& Dunitz, 1979). Both our study and that of Seiler \& Dunitz confirm the occurrence of disorder above the phase transition. Clearly, if rotational disorder of the rings is present, the supposition that individual ferrocene molecules must be staggered is not valid. Rather, the center of inversion at the $\mathrm{Fe}$ atom may result from superposition of molecules in several orientations, randomly distributed in domains throughout the crystal. Preliminary results of an X-ray study below the phase transition (Seiler \& Dunitz, 1979) have indicated that the low-temperature structure is triclinic, and contains an ordered arrangement of ferrocene molecules that are neither eclipsed nor staggered, although somewhat closer to the former configuration.

For a review of the structure of ferrocene and related compounds, the reader is referred to the preceding paper (Seiler \& Dunitz, 1979).

\section{Experimental}

Crystal data for ferrocene at 173 and $298 \mathrm{~K}$ are given in Table 1. The X-ray and neutron values at each temperature are in satisfactory agreement and also agree to within experimental error with the precise cell parameters determined as a function of temperature by X-ray powder diffraction techniques (Calvarin \& Bérar, 1975).

The sample of ferrocene used in the present work was recrystallized from benzene. The crystal was ground to form a cylinder of diameter $1.5 \mathrm{~mm}$ and height $5.5 \mathrm{~mm}$, and mounted on an aluminum pin along the crystallographic [ $\overline{2} 10]$ direction. It was sealed in a glass capillary and placed on an automated four-circle diffractometer (Dimmler, Greenlaw, Kelley, Potter, Rankowitz \& Stubblefield, 1976; McMullan, Andrews, Koetzle, Reidinger, Thomas \& Williams, 1976) at the Brookhaven High Flux Beam Reactor. Intensities were measured for reflections in two octants of reciprocal space, with a crystal-monochromated neutron beam of wavelength $1.0399 \AA$ (based on $\mathrm{KBr}, a=6.600 \AA$ ), by a $\theta / 2 \theta$ step-scan technique. Upper $2 \theta$ limits were $80^{\circ}$ for the room-temperature $(298 \mathrm{~K})$ measurements and $90^{\circ}$ for those at $173 \mathrm{~K} .^{*}$ The scan range was varied

* For the low-temperature measurements, the crystal was placed in a specially adapted closed-cycle helium refrigerator (Air Products and Chemicals, Inc. DISPLEX ${ }^{\oplus}$ model CS-202).

Table 1. Crystal data

$\mathrm{Fe}\left(\eta^{5}-\mathrm{C}_{5} \mathrm{H}_{5}\right)_{2}, \mathrm{C}_{10} \mathrm{H}_{10} \mathrm{Fe}, M_{r}=186 \cdot 04$, space group $P 2_{1} a(Z=2)$ Cell dimensions

\begin{tabular}{|c|c|c|c|c|}
\hline & $\begin{array}{c}\text { X-ray } \\
(298 \mathrm{~K})\end{array}$ & $\begin{array}{l}\text { Neutron } \\
(298 \mathrm{~K})\end{array}$ & $\begin{array}{c}\text { X-ray } \\
(173 \mathrm{~K})^{*}\end{array}$ & $\begin{array}{l}\text { Neutron } \\
(173 \mathrm{~K})\end{array}$ \\
\hline$a$ & $\begin{array}{c}10.528(2) \AA \\
7.602(1)\end{array}$ & $\begin{array}{c}10.530(8) \AA \\
7.604(5)\end{array}$ & $\begin{array}{c}10.45 \AA \\
7.58\end{array}$ & $\begin{array}{c}10.443(5) \AA \\
7.572(4)\end{array}$ \\
\hline$c$ & 5.923 (1) & $5.921(4)$ & $5 \cdot 81$ & $5 \cdot 824(4)$ \\
\hline$\beta$ & $121.05(1)^{\circ}$ & $121.05(8)^{\circ}$ & $120.86^{\circ}$ & $120.95(8)^{\circ}$ \\
\hline $\bar{X}$ & $406 \cdot 1(1) \AA^{3}$ & $406 \cdot 2(7) \AA^{3}$ & $395 \cdot 2 \AA^{3}$ & $395.0(5) \AA^{3}$ \\
\hline
\end{tabular}

Linear absorption coefficients

$$
\begin{aligned}
& \mu(\mathrm{X} \text {-ray, Mo } K \bar{\alpha}) \\
& \mu(\text { neutron, } \lambda=1.0399 \AA)=1.82 \mathrm{~mm}^{-1} \\
& \text { * Seiler \& Dunitz (1979). }
\end{aligned}
$$


according to $\Delta 2 \theta=1.76^{\circ}(1+6.90 \tan \theta)$ for $2 \theta>$ $50^{\circ}$ and $\Delta 2 \theta=4.00^{\circ}$ for $2 \theta \leq 50^{\circ}$. The step size was adjusted to give approximately 70 points in each scan. As a general check on experimental stability, the intensities of two reflections were remeasured every 100 reflections. These did not vary significantly during either the room- or low-temperature measurements.

Background corrections were made by a program (Takusagawa, 1977) written for a PDP 11/40 computer with an interactive graphics display (Vector General, Inc., 1973). Peak widths were initially calculated as $\Delta 2 \theta=A \tan \theta+B$, where $A$ and $B$ were determined by least squares from the strong reflections $[I>15 \sigma(I)]$, the widths of which were estimated directly from the peak profiles. (The fit was performed separately for reflections with $2 \theta$ values above and below $50^{\circ}$, resulting in two intersecting curves.) Final delineation of peak and background was made by a modification of the method of Lehmann \& Larsen (1974). Profiles of reflections with weak net intensity or unusual backgrounds were displayed, and the most suitable background curves were estimated manually.

Absorption corrections were calculated from the cylindrical shape of the crystal, and standard deviations were estimated as $\sigma^{2}(I)=T+B+[0.025(T-B)]^{2}+$ $(0.04 B)^{2}$, where $T$ and $B$ are the total and background counts, respectively, summed over the points in the peak, and the factors 0.025 and 0.04 represent estimates of non-Poisson errors. Squared observed structure factors were obtained as $F_{0}^{2}=I \sin 2 \theta$ and averaged for symmetry-related reflections. Agreement factors $\left(\boldsymbol{R}_{c}\right)$ are included in Table 2 , which gives some experimental details and summarizes the subsequent refinements.

Initial least-squares refinements were carried out with our room-temperature X-ray data. [X-ray data were collected at $298 \mathrm{~K}$ on a Picker diffractometer with Nb-filtered Mo $K \alpha$ radiation $(\lambda=0.71069 \AA)$. The crystal was ground to form a sphere $0.35 \mathrm{~mm}$ in

Table

\section{Experimental details and refinement parameters}

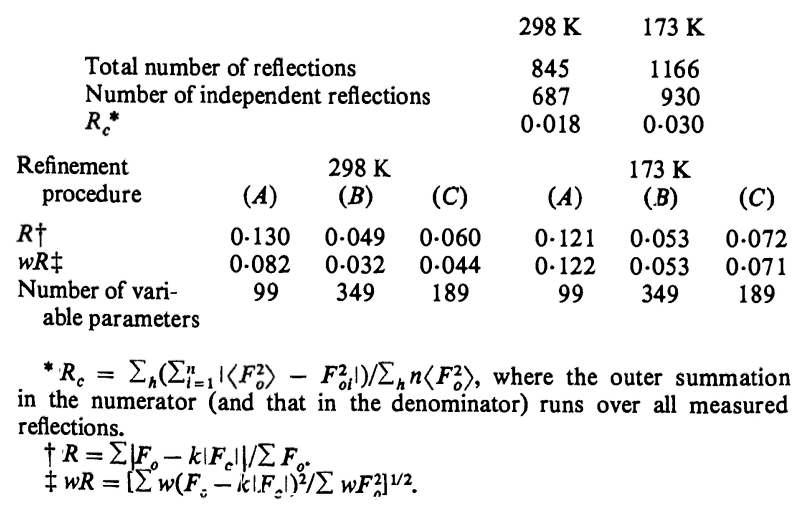

diameter. Intensities were measured over a hemisphere in reciprocal space, out to $2 \theta=70^{\circ}$, with a $\theta / 2 \theta$ stepscan technique. A correction was applied for a small amount of decay ( $\mathrm{ca} 2 \%$ ) in the intensities of the two monitor reflections. Azimuthal scans showed a few per cent variation in absorption, presumably due to deviations of the crystal from a spherical shape, so absorption corrections were made by a semi-empirical method (North, Phillips \& Mathews, 1968). The observed intensities were converted to squared structure factors, and averaged for symmetry-related reflections ( $R_{c}=0.011,1422$ independent reflections). All five C atoms were located in a Fourier map phased by the $\mathrm{Fe}$ atom fixed at the origin. Least-squares refinements were carried out by procedures $A$, and $B$ and $C$, as defined below. Unweighted $R$ values (based on $F$ ) are $0.061,0.050$ and 0.049 for procedures $A, B$ and $C$ respectively (the last cycles were carried out with parameters for $\mathbf{H}$ atoms fixed at the values determined from the $298 \mathrm{~K}$ neutron data). Results of the conventional full-matrix anisotropic refinement $(A)$ do not differ substantially from those obtained at room temperature by Seiler \& Dunitz (1979) and the geometry is very similar to that of the earlier DOR structure.] A Fourier map prepared with the $298 \mathrm{~K}$ neutron data, with phases calculated from the parameters for $\mathrm{Fe}$ and $\mathrm{C}$ atoms determined in the conventional X-ray refinement, showed five broad negative peaks denoting $\mathrm{H}$ atoms. Starting from this model, refinements were carried out by three procedures as indicated below, minimizing $\sum w\left(F_{o}-k\left|F_{c}\right|\right)^{2}$ where $w=4 F_{o}^{2} / \sigma^{2}\left(F_{o}^{2}\right)$, and neglecting reflections with $F_{o}^{2}<3 \sigma\left(F_{o}^{2}\right)(R$ values are included in Table 2$)$.

$(A)$ Positional and second-order thermal parameters $\left(U_{i j}\right)$ were varied, together with a type I Lorentzian isotropic extinction parameter (Becker \& Coppens, 1975), a scale factor, and the coherent neutron scattering length of Fe. A modified version of the program by Busing, Martin \& Levy (1962) was employed in these full-matrix anisotropic refinements. The most significant extinction correction is 0.900 (on $F$ ) for reflection 110 at $298 \mathrm{~K}$.

$(B)$ Difference maps calculated from the results of refinement $(A)$ showed significant peaks indicative of the presence of curvilinear or anharmonic thermal motion, or disorder, especially in the vicinity of the $\mathrm{H}$ atoms. Therefore, third- and fourth-order thermal tensors were introduced for the $\mathrm{C}$ and $\mathrm{H}$ atoms (Johnson, 1970a,b) and these higher-order terms were refined, as well as the parameters varied in procedure $(A){ }^{*} R$ values for procedure $(B)$ are substantially lower than those obtained in the conventional refinement, and no significant peaks were found in the resulting

\footnotetext{
* The extinction correction was of the form introduced by Zachariasen (1967). Parameters for $\mathrm{C}$ and $\mathrm{H}$ atoms were varied in alternate cycles; the scale and extinction parameters together with those for the $\mathrm{Fe}$ atom were included as variables in each cycle.
} 
difference maps. According to Hamilton's (1965) $R$ value test, procedure $(B)$ gives a significantly better fit to the data than do procedures $(A)$ or $(C)$ (see below) at the $99.5 \%$ significance level.

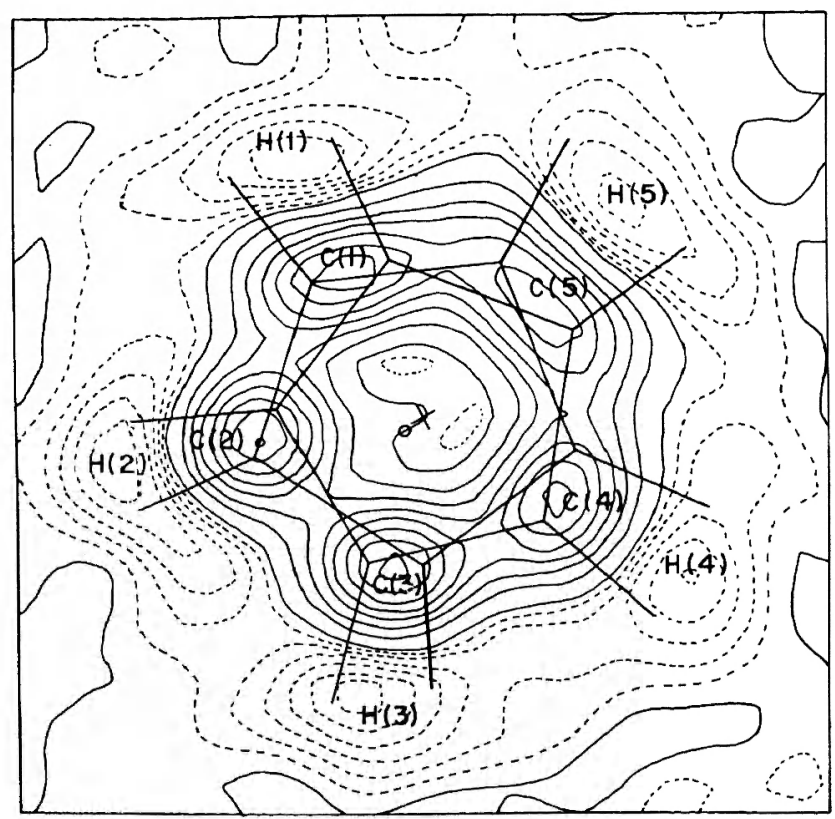

(a)

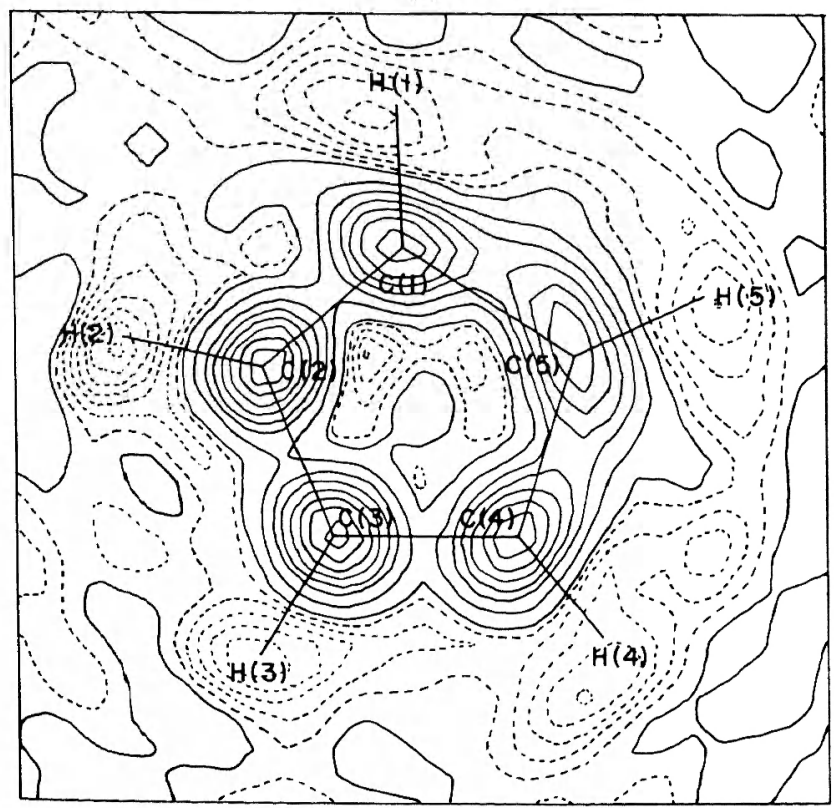

(b)

Fig. 1. Observed nuclear scattering-density map sections through the plane of the cyclopentadienyl ring. Negative contours are dashed and contour intervals are 0.2 and $0.067 \times 10^{-11} \mathrm{~mm}$ $\AA^{-3}$, for positive and negative contours respectively. (a) Map at $298 \mathrm{~K}$. Atomic positions from the disordered model, refinement $(C)$, are superimposed. $x$ and $O$ denote the ring centroid and center of rotation respectively. (b) Map at $173 \mathrm{~K}$. Atomic positions from refinement $(B)$ with higher-order thermal parameters are superimposed.
(C) A model with disordered cyclopentadienyl ligands was introduced, as an alternative way of fitting the observed nuclear scattering density which exhibits very broad peaks (Fig. 1). The initial trial model was refined by rigid-body least squares. Subsequently, individual atomic positional parameters and then anisotropic thermal parameters were refined in a stepwise fashion, first for all $\mathrm{H}$ and then for $\mathrm{C}$ atoms. Positional and thermal parameters were refined separately, as the refinement did not converge when they were allowed to vary simultaneously. Finally, all positional parameters were placed in one block, and thermal parameters in another [the thermal parameters and scattering length for the $\mathrm{Fe}$ atom, together with the scale and extinction parameters (Becker \& Coppens, 1975), were included in each block], and these were varied alternately until the maximum shifts were $<0.5 \sigma$.

Neutron scattering lengths (all $\times 10^{-11} \mathrm{~mm}$ ) are $b_{\mathrm{c}}=$ $0.665, b_{\mathrm{H}}=-0.374$ (Shull, 1972) and $b_{\mathrm{Fe}}=0.924$ (7) for $298 \mathrm{~K}$ and $0.902(7)$ for $173 \mathrm{~K}$. [The latter refined values for $\mathrm{Fe}$ are somewhat below the value of $0.951 \times$ $10^{-11} \mathrm{~mm}$ given by Shull (1972).] Final positional parameters obtained by the three refinement procedures are listed in Table $3 .^{*}$

\section{Results}

Sections of the nuclear scattering-density maps through the cyclopentadienyl ligands at 298 and $173 \mathrm{~K}$ are shown in Fig. 1. Bond distances and angles in the fivemembered ring calculated from the positional parameters obtained in refinement $(A)$ are shown in Fig. 2 together with displacements of $\mathrm{H}$ atoms from the best least-squares plane through the $\mathrm{C}$ atoms (the five $\mathrm{C}$ atoms are coplanar to within $0.003 \AA$ ). At $173 \mathrm{~K}$, all $\mathrm{H}$ atoms are found to be displaced out of the plane toward the $\mathrm{Fe}$ atom. The mean displacement is 0.030 (7) $\AA$, corresponding to an inclination of the $\mathrm{C}-\mathrm{H}$ vector to the plane of $1.6(4)^{\circ}$. [The corresponding values calculated with the positional parameters from refinement $(B)$ are $0.032(7) \AA$ and $1.7(4)^{\circ}$.] From gasphase electron diffraction data (Bohn \& Haaland, 1966; Haaland \& Nilsson, 1968) an inclination toward the metal of $3.7(9)^{\circ}$ has been calculated (Gard, Haaland, Novak \& Seip, 1975).

No dramatic difference is observed between the scattering density in the plane of the ring at $298 \mathrm{~K}$ (Fig. $1 a$ ), and $173 \mathrm{~K}$ (Fig. 1 b). In particular, the smearing of peaks by means of apparent hindered rotation about an

* Lists of thermal parameters and observed and calculated structure factors for neutron data at 173 and $298 \mathrm{~K}$ and X-ray data at $298 \mathrm{~K}$ have been deposited with the British Library Lending Division as Supplementary Publication No. SUP 34100 (30 pp.). Copies may be obtained through The Executive Secretary, International Union of Crystallography, 5 Abbey Square, Chester CH1 2HU, England. 
Table 3. Atomic coordinates

$298 \mathrm{~K}$

Refinement procedure $(A)$

$\begin{array}{lccc} & x & y & z \\ \mathrm{Fe} & 0.0000 & 0.0000 & 0.0000 \\ \mathrm{C}(1) & 0.0202(4) & 0.2602(3) & -0.032(1) \\ \mathrm{C}(2) & 0.0402(4) & 0.1763(4) & -0.2178(9) \\ \mathrm{C}(3) & 0.1584(4) & 0.0628(5) & -0.0902(9) \\ \mathrm{C}(4) & 0.2187(5) & 0.0680(5) & 0.1733(9) \\ \mathrm{C}(5) & 0.1327(6) & 0.1946(6) & 0.228(1) \\ \mathrm{H}(1) & -0.058(1) & 0.348(2) & -0.049(3) \\ \mathrm{H}(2) & -0.014(1) & 0.186(1) & -0.395(3) \\ \mathrm{H}(3) & 0.199(1) & -0.017(1) & -0.159(2) \\ \mathrm{H}(4) & 0.298(2) & 0.002(2) & 0.293(2) \\ \mathrm{H}(5) & 0.143(1) & 0.237(1) & 0.406(3)\end{array}$

Refinement procedure $(B)$

\begin{tabular}{lrrr}
$\mathrm{Fe}$ & 0.0000 & 0.0000 & 0.0000 \\
$\mathrm{C}(1)$ & $0.0183(2)$ & $0.2631(2)$ & \multicolumn{1}{c}{$-0.0315(5)$} \\
$\mathrm{C}(2)$ & $0.0428(2)$ & $0.1742(2)$ & $-0.2116(4)$ \\
$\mathrm{C}(3)$ & $0.1618(2)$ & $0.0634(2)$ & $-0.0877(5)$ \\
$\mathrm{C}(4)$ & $0.2155(2)$ & $0.0707(3)$ & $0.1775(5)$ \\
$\mathrm{C}(5)$ & $0.1306(3)$ & $0.1970(3)$ & $0.2214(5)$ \\
$\mathrm{H}(1)$ & $-0.0624(7)$ & $0.3519(6)$ & $-0.064(2)$ \\
$\mathrm{H}(2)$ & $-0.0205(7)$ & $0.1906(8)$ & $-0.409(1)$ \\
$\mathrm{H}(3)$ & $0.1976(6)$ & $-0.0202(7)$ & $-0.169(1)$ \\
$\mathrm{H}(4)$ & $0.3067(6)$ & $-0.0028(9)$ & $0.314(1)$ \\
$\mathrm{H}(5)$ & $0.141(1)$ & $0.239(1)$ & $0.403(1)$ \\
$\mathrm{Refinemen}$ & $\mathrm{procedure}(C)$ & & \\
$\mathrm{Fe}$ & 0.0000 & 0.0000 & 0.0000 \\
$\mathrm{C}(1 A)$ & $0.0020(6)$ & $0.2611(5)$ & $-0.0907(8)$ \\
$\mathrm{C}(1 B)$ & $0.0374(5)$ & $0.2619(5)$ & $0.028(1)$ \\
$\mathrm{C}(2 A)$ & $0.0426(8)$ & $0.1623(7)$ & $-0.240(2)$ \\
$\mathrm{C}(2 B)$ & $0.0398(7)$ & $0.1923(8)$ & $-0.186(1)$ \\
$\mathrm{C}(3 A)$ & $0.1726(8)$ & $0.056(1)$ & $-0.051(1)$ \\
$\mathrm{C}(3 B)$ & $0.1442(8)$ & $0.0713(9)$ & $-0.124(1)$ \\
$\mathrm{C}(4 A)$ & $0.2069(7)$ & $0.0924(8)$ & $0.217(1)$ \\
$\mathrm{C}(4 B)$ & $0.2196(5)$ & $0.0584(6)$ & $0.141(1)$ \\
$\mathrm{C}(5 A)$ & $0.0931(7)$ & $0.2306(6)$ & $0.188(1)$ \\
$\mathrm{C}(5 B)$ & $0.1587(5)$ & $0.1720(7)$ & $0.258(1)$ \\
$\mathrm{H}(1 A)$ & $-0.084(2)$ & $0.346(2)$ & $-0.159(4)$ \\
$\mathrm{H}(1 B)$ & $-0.045(2)$ & $0.348(2)$ & $-0.001(4)$ \\
$\mathrm{H}(2 A)$ & $0.003(2)$ & $0.155(2)$ & $-0.418(4)$ \\
$\mathrm{H}(2 B)$ & $-0.035(2)$ & $0.214(2)$ & $-0.391(3)$ \\
$\mathrm{H}(3 A)$ & $0.221(2)$ & $-0.026(2)$ & $-0.085(3)$ \\
$\mathrm{H}(3 B)$ & $0.179(2)$ & $-0.012(2)$ & $-0.231(3)$ \\
$\mathrm{H}(4 A)$ & $0.293(2)$ & $0.022(2)$ & $0.375(3)$ \\
$\mathrm{H}(4 B)$ & $0.313(1)$ & $-0.026(2)$ & $0.256(4)$ \\
$\mathrm{H}(5 A)$ & $0.078(4)$ & $0.293(2)$ & $0.329(5)$ \\
$\mathrm{H}(5 B)$ & $0.181(2)$ & $0.197(3)$ & $0.452(3)$
\end{tabular}

$173 \mathrm{~K}$

\begin{tabular}{lcc}
\multicolumn{1}{c}{$x$} & $y$ & \multicolumn{1}{c}{$z$} \\
0.0000 & 0.0000 & 0.0000 \\
$0.0203(3)$ & $0.2626(3)$ & $-0.0317(8)$ \\
$0.0398(3)$ & $0.1777(3)$ & $-0.2201(6)$ \\
$0.1578(3)$ & $0.0656(3)$ & $-0.0943(5)$ \\
$0.2181(3)$ & $0.0716(4)$ & $0.1756(6)$ \\
$0.1327(5)$ & $0.1977(5)$ & $0.2283(6)$ \\
$-0.062(1)$ & $0.3543(8)$ & $-0.053(3)$ \\
$-0.024(1)$ & $0.193(1)$ & $-0.414(2)$ \\
$0.201(1)$ & $-0.024(1)$ & $-0.179(2)$ \\
$0.3094(9)$ & $-0.005(1)$ & $0.321(2)$ \\
$0.150(2)$ & $0.234(2)$ & $0.420(2)$
\end{tabular}

\begin{tabular}{lcc}
0.0000 & 0.0000 & 0.0000 \\
$0.0194(2)$ & $0.2645(2)$ & \multicolumn{1}{c}{$-0.0261(5)$} \\
$0.0386(2)$ & $0.1798(2)$ & $-0.2200(3)$ \\
$0.1580(2)$ & $0.0646(2)$ & $-0.0966(4)$ \\
$0.2203(2)$ & $0.0694(2)$ & $0.1739(4)$ \\
$0.1392(3)$ & $0.1927(3)$ & $0.2342(4)$ \\
$-0.0641(7)$ & $0.3569(5)$ & \multicolumn{1}{c}{$-0.053(2)$} \\
$-0.0251(6)$ & $0.1921(8)$ & $-0.4217(9)$ \\
$0.1980(6)$ & $-0.0217(7)$ & $-0.180(1)$ \\
$0.3094(5)$ & $-0.0038(9)$ & $0.319(1)$ \\
$0.152(1)$ & $0.232(1)$ & $0.420(1)$ \\
& & \\
0.0000 & 0.0000 & 0.0000 \\
$0.0051(6)$ & $0.2615(6)$ & $-0.0824(9)$ \\
$0.0358(5)$ & $0.2636(5)$ & $0.025(1)$ \\
$0.0426(6)$ & $0.1643(6)$ & $-0.241(1)$ \\
$0.0375(6)$ & $0.1945(6)$ & $-0.1901(8)$ \\
$0.1740(6)$ & $0.0579(9)$ & $-0.049(1)$ \\
$0.1464(5)$ & $0.0703(7)$ & $-0.1224(8)$ \\
$0.2067(8)$ & $0.0941(8)$ & $0.213(1)$ \\
$0.2220(5)$ & $0.0597(6)$ & $0.150(1)$ \\
$0.0959(8)$ & $0.2290(7)$ & $0.191(1)$ \\
$0.1596(6)$ & $0.1761(7)$ & $0.2618(9)$ \\
$-0.079(2)$ & $0.356(2)$ & $-0.140(5)$ \\
$-0.051(2)$ & $0.351(1)$ & $-0.008(5)$ \\
$-0.013(3)$ & $0.167(3)$ & $-0.438(3)$ \\
$-0.033(2)$ & $0.215(2)$ & $-0.397(4)$ \\
$0.220(2)$ & $-0.030(3)$ & $-0.105(5)$ \\
$0.180(2)$ & $-0.012(2)$ & $-0.234(3)$ \\
$0.297(2)$ & $0.019(3)$ & $0.371(3)$ \\
$0.316(2)$ & $-0.024(2)$ & $0.267(5)$ \\
$0.087(5)$ & $0.286(3)$ & $0.350(7)$ \\
$0.177(2)$ & $0.206(3)$ & $0.445(3)$ \\
& & \\
& &
\end{tabular}

axis normal to the ring* persists to a great extent at the lower temperature. The thermal parameters $U_{i j}$ from refinement $(A)$ have been subjected to rigid-body analysis (Cruickshank, 1956; Schomaker \& Trueblood, 1968), the results of which are summarized in Table 4. Mean-square amplitudes of translational vibration are reduced by proportions comparable to the ratio of absolute temperatures, as expected, but the large

\footnotetext{
* This axis does not pass through the ring center, since the smearing at $C(1)$ and $C(5)$ is greater than that at $C(2), C(3)$ and C(4).
}

amplitudes of libration about the axis normal to the ring are hardly affected by lowering the temperature. It is thus reasonable to conclude that the structural disorder apparent in the maps of Fig. 1 is primarily static in character, resulting from the presence of molecules in different orientations randomly distributed throughout the crystal. The $R$ values for the $\mathrm{X}$-ray data are quite reasonable $(\sim 0.06)$ and it is only in the neutron study that the existence of disorder becomes obvious.

Agreement factors for refinement $(B)$, incorporating higher-order thermal tensors, are somewhat lower thar. 
those for $(C)$, incorporating the twofold disorder model. Obviously, there is no particular reason to favor a twofold model over any of a large number of other possible disordered models, based on the present neutron diffraction study.

\section{Discussion}

An important conclusion of the present study is that the $\mathrm{H}$ atoms on the cyclopentadienyl ligands are displaced significantly toward the $\mathrm{Fe}$ atom. Electron diffraction results have indicated the same direction of displacement in both ferrocene [0.07 (2) $\AA$, corresponding to an inclination of the $\mathrm{C}-\mathrm{H}$ vector to the plane of $\left.3.7(9)^{\circ}\right]$ and $\left(\mathrm{Cp}_{2}\right) \mathrm{Cr}^{*}\left[0.06(2) \AA\right.$ or $\left.2.9(1.1)^{\circ}\right]$, but

* Abbreviations: Cp cyclopentadienyl, Me methyl, $\mathrm{Ph}$ phenyl.

Table 4. Rigid-body analysis of thermal motion, based on $U_{i v}$ values determined in refinement $(A)$

The units for mean-square amplitude of translational vibration (T), librational vibration $(\mathrm{L})$, and root-mean-square fit $\left\langle\Delta U^{2}\right\rangle^{1 / 2}$ are $0.0001 \AA^{2}, 0.0001 \mathrm{rad}^{2}$ and $0.0001 \AA^{2}$ respectively.

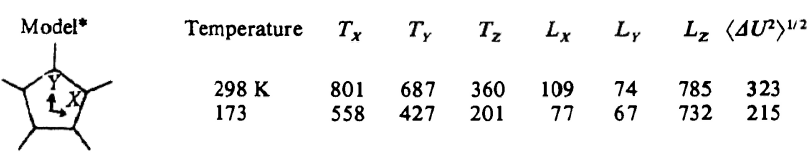

* The coordinate system used in these calculations is indicated by arrows $X$ and $Y$. The $Z$ coordinate is taken in the direction perpendicular to the page. The screw tensor was set identically to zero.

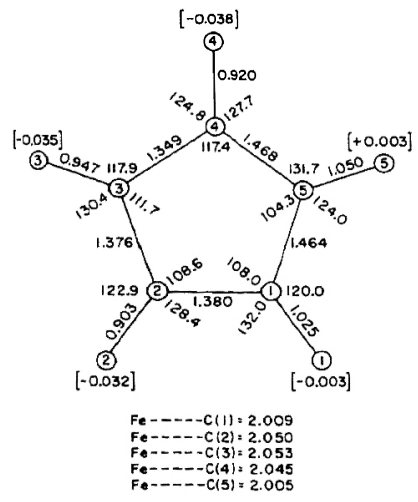

(a)

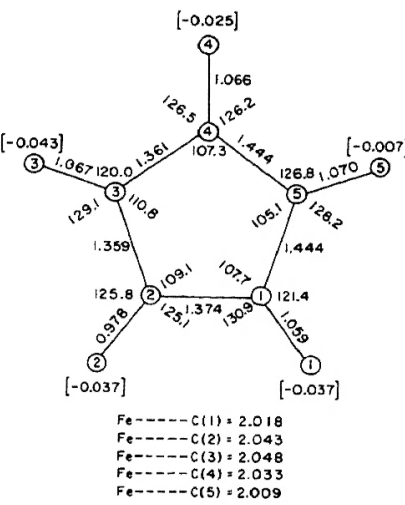

(b)
Fig. 2. Bond distances $(\AA)$ and angles $\left(^{\circ}\right)$, and displacements $(\AA)$ from the least-squares plane through the cyclopentadienyl ring (e.s.d.'s of displacements from the plane are less than or equal to those of $\mathbf{C}-\mathbf{H}$ bond distances; negative displacements are taken toward the $\mathrm{Fe}$ atom), calculated with atomic coordinates from refinement $(A)$. (a) Results at $298 \mathrm{~K}$; e.s.d.'s: C $-\mathrm{C}=0.005 \sim$ $0.009 \AA, \mathrm{Fe}-\mathrm{C}=0.003 \sim 0.005 \AA, \mathrm{C}-\mathrm{H}=0.014 \sim 0.020 \AA$, $\angle \mathrm{C}-\mathrm{C}-\mathrm{C}=0.4 \sim 0.5^{\circ}, \angle \mathrm{C}-\mathrm{C}-\mathrm{H}=0.7 \sim 1.2^{\circ}$. (b) Results at $173 \mathrm{~K}$; e.s.d.'s: $\mathrm{C}-\mathrm{C}=0.003 \sim 0.006 \AA, \mathrm{Fe}-\mathrm{C}=0.003 \sim$ $0.004 \AA, \mathbf{C}-\mathrm{H}=0.009 \sim 0.015 \AA, \angle \mathrm{C}-\mathrm{C}-\mathrm{C}=0.2 \sim 0.3^{\circ}$, $\angle \mathrm{C}-\mathrm{C}-\mathrm{H}=0.6 \sim 1.0^{\circ}$. no significant displacement was found in $(\mathrm{Cp})_{2} \mathrm{~V}$ or $(\mathrm{Cp})_{2} \mathrm{Ni}$ (Gard, Haaland, Novak \& Seip, 1975). From these results, it has been concluded that in sandwich compounds the inclination angle or displacement of the $\mathrm{H}$ atoms toward the metal should vary inversely with the metal-Cp distance. In a neutron diffraction study of ferrocenedicarboxylic acid (Takusagawa \& Koetzle, 1979), we have observed a mean displacement toward the metal of 0.027 (5) $\AA$ or $1.4(3)^{\circ}$. On the other hand, we have been unable to detect any general systematic displacement of the $\mathrm{H}$ atoms toward the $\mathrm{Ni}$ atoms in $\mathrm{H}_{3} \mathrm{Ni}_{4}(\mathrm{Cp})_{4}$ (Koetzle et al., 1978). Of course, the displacements observed in the solid state would be expected to vary somewhat with crystalline environment.

In X-ray diffraction studies, a slight displacement of the $\mathrm{H}$ atoms toward the metal was observed in $(\mathrm{Cp})\left(\mathrm{Ph}_{3} \mathrm{P}\right) \mathrm{Cu}^{\mathrm{I}}$ (Cotton \& Takats, 1970), and dibenzenechromium (Keulen \& Jellinek, 1966). In a neutron diffraction study of benzenetricarbonylchromium (Rees \& Coppens, 1973) the mean displacement of the $\mathrm{H}$ atoms toward the $\mathrm{Cr}$ atom was found to be $0.03 \AA$, but possibly owing to steric effects the opposite sense of displacement of the methyl $\mathrm{C}$ atoms was found in an X-ray study of tricarbonylhexamethylbenzenechromium (Bailey \& Dahl, 1965). In bis(1,3,5,7-tetramethylcyclooctatetraenyl)uranium(IV), Hodgson \& Raymond (1973) have observed a mean displacement of the methyl $\mathrm{C}$ atoms towards the $\mathrm{U}$ atom of 0.10 (2) $\AA$, while in $\mathrm{H}_{3} \mathrm{Ir}_{2}\left(\mathrm{Me}_{5} \mathrm{Cp}\right)_{2}$ the methyl $\mathrm{C}$ atoms are found to be displaced 0.08 (1) $\AA$ away from the Ir atoms (Teller, 1978).

As indicated above, the results of the present refinements confirm that the ferrocene crystal structure is disordered at both 173 and $298 \mathrm{~K}$, thus invalidating the supposition that individual molecules must be staggered. In refinement $(C)$, incorporating the model with twofold disorder, the rings are found to be twisted by approximately $24^{\circ}$ with respect to one another. The

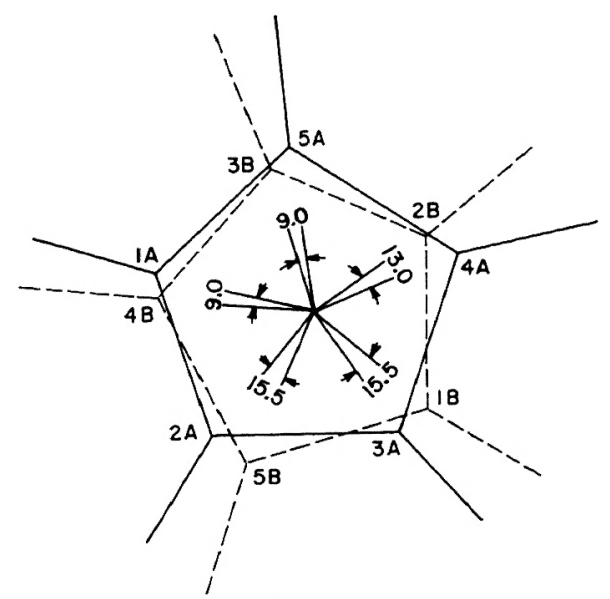

Fig. 3. Possible (nearly) eclipsed configuration for a ferrocene molecule, consistent with the disordered model, refinement $(C)$. 
rotation axis does not coincide with the center of the rings, as can be seen in Fig. 1(a). Such a disordered model could be regarded as resulting from the superposition of two staggered or two (nearly) eclipsed configurations. (In order to allow an exactly eclipsed configuration, the two disordered rings would have to be rotated $36^{\circ}$.) A possible configuration consistent with the present model $(C)$, with the two cyclopentadienyl rings rotated about $12^{\circ}$ from the eclipsed position, is indicated in Fig. 3. The disordered structure may then be rationalized in terms of a domain model, such as that illustrated in Fig. 4. However, it is important to emphasize that there is no particular uniqueness to the twofold model. As one might expect, a better fit to the observed nuclear scattering density is achieved in refinement $(B)$ by incorporating higherorder thermal tensors, and in fact the disorder may well involve a continuous range of molecular configurations. Finally, the bond distances and angles shown in Fig. 2 should not be regarded as representative of an individual ferrocene molecule.
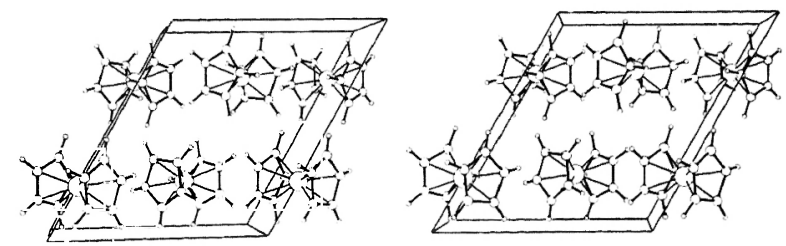

Fig. 4. Stereoscopic view (Johnson, 1976) of a possible domain structure incorporating a (nearly) eclipsed configuration, looking down $\mathbf{b}$ with a horizontal. Here $c$ is taken as twice that in the $P 2_{1} / a$ disordered structure, and an individual domain conforms to space group $P 2_{1} / n$. Seiler \& Dunitz (1979) have shown that the symmetry of the low-temperature (ordered) structure is actually triclinic.

We thank D. W. Hart for providing samples of ferrocene, Professor J. D. Dunitz for communicating his results to us prior to publication, B. T. M. Willis for helpful discussions, and J. Henriques for his technical assistance.

Note added in proof: Recently the X-ray diffraction study of ferrocene at 130 and $295 \mathrm{~K}$ by Clec'h, Calvarin, Bérar \& Kahn (1978) has come to our attention. The results of this study also show that the structure is disordered at room temperature, and ordered at $130 \mathrm{~K}$.

Quantitative comparisons have been made between the results of the conventional refinement $(A)$ in the present neutron diffraction study and the X-ray investigation reported in the preceding paper (Seiler \& Dunitz, 1979), bearing in mind that the comparisons are complicated by the presence of disorder. The $\mathrm{H}$-atom coordinates were refined in the present work, but fixed to yield reasonable bond distances and angles in the $\mathrm{X}$-ray determination. The neutron atomic coordinates for $\mathrm{C}$ atoms have e.s.d.'s that are smaller by up to a factor of two than those for the X-ray coordinates. For the $173 \mathrm{~K}$ results, differences in these coordinates are all less than $3 \sigma$ (pooled), while in the case of the room-temperature values two individual coordinates, $\mathrm{C}(1) x$ and $\mathrm{C}(3) y$, differ by $3-4 \sigma$ (pooled). A half-normal probability plot (Abrahams \& Keve, 1971) indicated that the pooled standard deviations in the $173 \mathrm{~K}$ coordinates may have been underestimated by about $40 \%$. Thermal parameters from the neutron study are generally somewhat larger than the corresponding $\mathrm{X}$-ray values.

\section{References}

Abrahams, S. C. \& Keve, E. T. (1971). Acta Cryst. A27, 157-165.

BAILEY, M. F. \& DAHL, L. F. (1965). Inorg. Chem. 4, 12981306.

BeCKer, P. J. \& Coppens, P. (1975). Acta Cryst. A31, 417 425.

Bohn, R. K. \& HaAland, A. (1966). J. Organomet. Chem. 5, 470-476.

Busing, W. R., Martin, K. O. \& Levy, H. A. (1962). ORFLS. Report ORNL-TM-305. Oak Ridge National Laboratory, Tennessee.

Calvarin, G. \& BéRAR, J. F. (1975). J. Appl. Cryst. 8, 380385.

Campbell, A. J., Fyfe, C. A., Harold-Smith, D. \& JefFrey, K. R. (1976). Mol. Cryst. Liq. Cryst. 36, 1-23.

Clec'h, G., Calvarin, G., Bérar, J. F. \& Kahn, R. (1978). C. R. Acad. Sci. Sér. C, 286, 315-317.

Cotton, F. A. \& TaKats, J. (1970). J. Am. Chem. Soc. 92, 2353-2358.

Cruickshank, D. W. J. (1956). Acta Cryst. 9, 754-756.

Dimmler, D. G., Greenlaw, N., Kelley, M. A., Potter, D. W., Rankowitz, S. \& Stubblefield, F. W. (1976). IEEE Trans. Nucl. Sci. NS23, 398-405.

Dunitz, J. D. \& OrgeL, L. E. (1953). Nature (London), $171,121-122$.

Dunitz, J. D., ORgel, L. E. \& Rich, A. (1956). Acta Cryst. 9, 373-375.

Edwards, J. W., Kington, G. L. \& Mason, R. (1960). Trans. Faraday Soc. 56, 660-667.

Eiland, P. F. \& Pepinsky, R. (1952). J. Am. Chem. Soc. 74, 4971.

Fischer, E. O. \& PfaB, W. (1952). Z. Naturforsch. Teil B, 7, 377-379.

Gard, E., HaAland, A., Novak, D. P. \& Seip, R. (1975). J. Organomet. Chem. 88, 181-189.

HaAland, A. \& Nilsson, J. E. (1968). Acta Chem. Scand. 22, 2653-2670.

Hamilton, W. C. (1965). Acta Cryst. 18, 502-510.

Hodgson, K. O. \& RaYmond, K. N. (1973). Inorg. Chem. $12,458-466$.

Johnson, C. K. (1970a). Annual Progress Report ORNL4581, pp. 133-134. Chemistry Division, Oak Ridge National Laboratory, Tennessee.

JohNSON, C. K. (1970b). ORJFLS. Unpublished. 
JoHNSON, C. K. (1976). ORTEP II. Report ORNL-5138. Oak Ridge National Laboratory, Tennessee.

KeUlen, E. \& Jellinek, F. (1966). J. Organomet. Chem. 5, 490-492.

Koetzle, T. F., McMullan, R. K., Bau, R., Hart, D. W., Teller, R. G., Tipton, D. L. \& Wilson, R. D. (1978). Adv. Chem. Ser. 67, 61-72.

Lehmann, M. S. \& Larsen, F. K. (1974). Acta Cryst. A 30, 580-584.

McMullan, R. K., Andrews, L. C., Koetzle, T. F., Reidinger, F., Thomas, R. \& Williams, G. J. B. (1976). NEXDAS. Neutron and X-ray data acquisition system. Unpublished.

North, A. C. T., Phillips, D. C. \& Mathews, F. S. (1968). Acta Cryst. A24, 351-359.

ReES, B. \& Coppens, P. (1973). Acta Cryst. B29, 25152528.

Acta Cryst. (1979). B35, 1081-1084
Schomaker, V. \& Trueblood, K. N. (1968). Acta Cryst. B24, 63-76.

Seiler, P. \& Dunitz, J. D. (1979). Acta Cryst. B35, 10681074.

Shull, C. G. (1972). Private communication.

TAKusagawa, F. (1977). PEAK. Unpublished.

TAKusagawa, F. \& Koetzle, T. F. (1979). To be published.

Teller, R. G. (1978). PhD Thesis, Univ. of Southern California.

Vector General, Inc. (1973). Fortran Drawing Package Reference Manual. 8399 Topanga Canyon Blvd., Canoga Park, CA 91304, USA.

Willis, B. T. M. (1960). Acta Cryst. 13, 1088.

WILlis, B. T. M. (1961). AERE Report R3708, Harwell, Oxfordshire, England.

ZACHARIASEN, W. H. (1967). Acta Cryst. 23, 558-564.

\title{
The Crystal Structure of Bis(n-butylammonium) Tetrachloromanganate(II), $\left(n-\mathrm{C}_{4} \mathrm{H}_{9} \mathrm{NH}_{3}\right)_{2} \mathrm{MnCl}_{4}$, at $294 \mathrm{~K}$
}

\author{
BY W. DEPMEIER \\ Universität Konstanz, FB Chemie, Postfach 7733, D 7750 Konstanz, Federal Republic of Germany* \\ AND G. Chapuis \\ Université de Lausanne, Institut de Cristallographie, 'BSP Dorigny, CH 1015 Lausanne, Switzerland
}

(Received 23 November 1978; accepted 2 January 1979)

\begin{abstract}
$\operatorname{Bis}(n$-butylammonium) tetrachloromanganate(II), $2 \mathrm{C}_{4} \mathrm{H}_{12} \mathrm{~N}^{+} . \mathrm{MnCl}_{4}^{2-},\left[\mathrm{NH}_{3} \mathrm{C}_{4} \mathrm{H}_{9}\right]_{2}\left[\mathrm{MnCl}_{4}\right]$, crystallizes in a perovskite-type layer structure with $a=7.3356(6)$, $b=7.2512(8), c=31.880$ (6) $\AA$, space group $A b m a$, $Z=4$. Its structure has been refined to $R=0.049$ $\left(R_{w}=0.041\right)$ with 516 independent reflexions. The $\mathrm{N}-\mathrm{H} \cdot \mathrm{Cl}$ hydrogen-bonding system and the butylammonium groups are disordered as in the roomtemperature phases of the ethyl and propyl homologues. The butylammonium chain, however, has a different conformation: $\mathrm{N}-\mathrm{C}(1)-\mathrm{C}(2)-\mathrm{C}(3)$ are alltrans, but the terminal $\mathrm{C}(4)$ is gauche.
\end{abstract}

\section{Introduction}

In recent years, much work has been done on the structures, phase transitions, lattice dynamics and two-

* Present address: Département de Chimie Minerale, Analytique et Appliquée de l'Université, 30 quai Ernest Ansermet, $\mathrm{CH} 1211$ Genève, Switzerland.

0567-7408/79/051081-04\$01.00 dimensional magnetism of the $\mathrm{K}_{2} \mathrm{NiF}_{4}$-type compounds $\left(\mathrm{C}_{n} \mathrm{H}_{2 n+1} \mathrm{NH}_{3}\right)_{2} M_{\mathrm{Cl}_{4}}$ with $M=\mathrm{Mn}, \mathrm{Cd}, \mathrm{Fe}, \mathrm{Cu}, \mathrm{Pd}$ (see, e.g., Arend, Huber, Mischgofsky \& Richter-van Leeuwen, 1978, and literature cited therein). All these compounds undergo structural phase transitions, up to as many as five in $\left(\mathrm{C}_{3} \mathrm{H}_{7} \mathrm{NH}_{3}\right)_{2} \mathrm{MnCl}_{4}$. This particular compound shows commensurate and incommensurate superstructures at various temperatures (Depmeier, Felsche \& Wildermuth, 1977). In a recent work (Depmeier, 1979, hereafter D79) it has been reported that the propyl compound in the series $\left(\mathrm{C}_{n} \mathrm{H}_{2 n+1} \mathrm{NH}_{3}\right)_{2} \mathrm{MnCl}_{4}$ with $n=1-10$ exhibits some unique properties, e.g. it has the largest distortion of the $\mathrm{MnCl}_{6}$ octahedra and the highest transition temperature to a fully disordered state. A possible reason for these characteristics was given on the basis of packing modes of the different alkyl chains. In the initial stages of D79 it was known from single-crystal structure determinations (Peterson \& Willett, 1972; Depmeier, 1976; Depmeier \& Mason, 1978; Depmeier \& Heger, 1978) that the ethyl and propyl compounds have some important structural features in common; in particular, both compounds have the same hydrogen(C) 1979 International Union of Crystallography 